\title{
Psychological Burden During the COVID-19 Pandemic in Germany
}

\author{
Iris Schelhorn ${ }^{* \dagger}$, Angelika Ecker ${ }^{+\dagger}$, Michael Noah Lüdtke ${ }^{3}$, Stefan Rehm ${ }^{3}$, Thomy Tran ${ }^{3}$, \\ Judith Lena Bereznai ${ }^{3}$, Marie Lisa Meyer ${ }^{3}$, Stefan Sütterlin ${ }^{4}$, Max Kinateder $^{5}$, \\ Ricardo Gregorio Lugo ${ }^{6}$ and Youssef Shiban ${ }^{3}$
}

\begin{abstract}
${ }^{1}$ Department of Educational Psychology, University of Regensburg, Regensburg, Germany, ${ }^{2}$ Clinic and Polyclinic for Child and Adolescent Psychiatry, Psychosomatics and Psychotherapy, University of Regensburg, Regensburg, Germany, ${ }^{3}$ Department of Psychology, Private University of Applied Sciences, Göttingen, Germany, ${ }^{4}$ Faculty of Health and Welfare Sciences, Østfold University College, Fredrikstad, Norway, ${ }^{5}$ National Research Council Canada (NRC-CNRC), Ottawa, ON, Canada, ${ }^{6}$ Faculty of Social and Health Sciences, Inland Norway University of Applied Sciences, Elverum, Norway
\end{abstract}

\section{OPEN ACCESS}

Edited by:

Bruria Adini,

Tel Aviv University, Israel

Reviewed by:

Hannah Kohler,

University of Duisburg-Essen,

Germany

Nora Dörrie,

LVR Hospital Essen, Germany

*Correspondence:

Iris Schelhorn

iris.schelhorn@ur.de

${ }^{\dagger}$ These authors have contributed equally to this work and share first authorship

Specialty section:

This article was submitted to

Psychology for Clinical Settings, a section of the journal

Frontiers in Psychology

Received: 11 December 2020

Accepted: 16 August 2021

Published: 07 September 2021

Citation

Schelhorn I, Ecker A, Lüdtke MN,

Rehm S, Tran T, Bereznai JL,

Meyer ML, Sütterlin S, Kinateder M,

Lugo RG and Shiban Y (2021)

Psychological Burden During

the COVID-19 Pandemic in Germany.

Front. Psychol. 12:640518.

doi: 10.3389/fpsyg.2021.640518
After the first COVID-19 case was diagnosed in Germany, various measures limiting contact between people were introduced across the country. The implementation of these measures varied between jurisdictions and potentially had a negative impact on the psychological well-being of many people. However, the prevalence, severity, and type of symptoms of psychological burden has not been documented in detail. In the current study, we analysed various self-reported symptoms of psychological burden in a German sample. The dataset was collected between April 8th and June 1st, 2020, through an online survey measuring psychological burden using the ICD10 -symptom rating scale. More than 2,000 individuals responded to the survey, with a total of 1,459 complete datasets. Data was then sampled to compare (1) the new data to an existing demographically comparable reference dataset including a total of 2,512 participants who did not undergo any kind of contact restrictions or other pandemic measurements, and (2) psychological burden in two different German states. In line with recent observations from Germany, Italy, China, Austria and Turkey, we found a high prevalence of depressive symptoms in comparison to the reference sample. Furthermore, we found a high prevalence of eating disorder and compulsion symptoms. Especially younger adults and women reported a higher symptom severity compared to other groups during our measurement period. However, no difference between the two states in psychological burden was found.

Keywords: COVID-19, psychological burden, Germany, depression, mental health

\section{INTRODUCTION}

The World Health Organization (WHO) declared a public health emergency of international concern on 30 January 2020 due to the COrona VIrus Disease 2019 (COVID-19). Such a declaration implies that a disease can potentially have a serious impact on public health, including mental health [World Health Organization (WHO), 2020]. Because of this declaration, many governments enacted public health interventions such as physical distancing, canceling leisure time activities, mandatory breaks for schools and universities, travel restrictions and obligatory quarantine for anyone tested positive for the disease. Some of these measures restricted personal movement and 
may therefore have led to social isolation. Both have been linked to an increase in stress-responses and even mortality rates (Grewen et al., 2003; Cacioppo et al., 2015; Holt-Lunstad et al., 2015; Conradi et al., 2020). The meta-analytic study of Holt-Lunstad et al. (2015) found increases in mortality rates of $32 \%$ for living alone, $26 \%$ for loneliness and $29 \%$ for social isolation. In addition, the economic consequences of the restrictions have begun taking their toll, for instance, through a sharp increase in unemployment and decreased employment security (e.g., in Germany). The economic consequences are likely to further amplify the psychosocial burden, given that loss of employment, for instance, is a highly stressful life event (Slavich and Shields, 2018). Therefore, it is not surprising that the prevalence of depression, but also of other mental disorders, has increased since the beginning of the COVID-19 pandemic and the implementation of measures to restrict social contact (e.g., Tang et al., 2020).

Recent studies concerning the psychological effects of the COVID-19 pandemic worldwide have shown an increased risk in mental disorders in different countries. Pieh et al. (2020) observed a prevalence of $21 \%$ for depression symptoms and $19 \%$ for anxiety symptoms in Austria over a 2-week period (until April 30th, 2020) following a 4-week lockdown due to the Covid19 pandemic. Comparable results were demonstrated in Italy (between March 27th and April 06th 2020) with the prevalence of disorder symptoms being $17.3 \%$ for depression and $20.8 \%$ for anxiety symptoms (Rossi et al., 2020). Wang et al. (2021) reported a prevalence of $17 \%$ for depression as well as a prevalence of $6 \%$ for anxiety symptomatology (from February 6 to February 9 2020) in a Chinese sample. In Turkey (between April 14 and April 16 2020) results show that $23 \%$ of the participants scored above the depression cut-off and $45 \%$ scored above the anxiety cutoff of the Hospital Anxiety and Depression Scale (Özdin and Bayrak Özdin, 2020). Similar results were found in Switzerland where de Quervain et al. (2020) investigated the impact of the COVID-19 pandemic on mental health where over half of the participants reported an increase in depressive symptoms during confinement compared to before the virus outbreak. In this study, those with a history of psychiatric disorders were more at risk than participants with no prior psychiatric issues whereas older people and men were more resilient. Other studies confirm these findings and also show that female participants had higher depression scores than men, were lonelier and suffered more from daily life fatigue (Bartoszek et al., 2020). Specifically for the German population, studies indicate comparable effects of the COVID-19 situation and the accompanying restrictions on mental health. A large study showed high prevalence for depressive symptoms, generalized anxiety disorder and general distress (Bäuerle et al., 2020b) and several studies indicate that the psychological burden is especially high for women (Bäuerle et al., 2020a; Peters et al., 2020; Petzold et al., 2020). Furthermore, the pandemic and the restrictions it entailed seemed to represent a greater psychological burden for younger compared to older people (Bäuerle et al., 2020b; Peters et al., 2020). Specifically, a study of Röhr et al. (2020) showed older people ( $>65$ years) to be more resilient regarding depression, anxiety and somatization symptoms. Another recent study focusing on health care staff in Germany showed that health care workers were less psychologically burdened than the comparison group regarding symptoms of depression, anxiety and fear of COVID in the first weeks of restrictions (Skoda et al., 2020).

In the present study, psychological well-being during the time of restrictions following the COVID-19 outbreak was explored in different regions of Germany, mainly Bavaria and Lower Saxony. This could be of interest, as due to the federal state structure of Germany and differences in impact of COVID-19, German states imposed different levels of curfew, while other factors influencing stress and well-being under a pandemic such as healthcare system infrastructure, availability and accessibility of healthcare systems (Brooks et al., 2020), are comparable across Germany. Furthermore, sociodemographic structures, economic situations, and trust in public authorities are equally comparable in all states. We explored psychological burden shortly after restrictions were introduced and compared them to a reference sample from 2010 (Tritt et al., 2010) containing non-clinical participants who did not undergo any kind of contact restrictions or other pandemic related measures. We were interested in different mental health syndromes: depression, anxiety, somatization, eating disorder symptoms, and compulsion. We hypothesized that there would be a high prevalence of depressive symptoms due to an increase in stress level. Furthermore, we hypothesized that the measures resulted in different levels of psychological stress and therefore reported symptoms in two different regions expecting higher levels in Bavaria than in Lower Saxony as the restrictions were more intense in the Bavarian region.

\section{MATERIALS AND METHODS}

\section{Study Design}

A cross-sectional design was used to collect survey data in a webbased questionnaire. The effects of age, gender, and region of residence on severity of symptoms were further explored. The 15min survey included additional questionnaires; however, those characteristics were outside the scope of the present analysis. The data was collected between April 8 and June 1 2020. The timeline of this study within the context of COVID-19 development is depicted in Figure 1.

\section{Sample}

Participants were recruited via flyers, social online platforms, mailing lists and notices in in-patient clinics and supermarkets. Out of 2,506 participants who had started the questionnaire, 1,739 datasets $(69.4 \%$ valid sets; $72.6 \%$ female) contained data that was usable for statistical analysis for this manuscript. We excluded 280 participants who reported to have been or were in psychotherapy, as the sample we used for comparison (reference sample) was a mentally healthy group of individuals. The resulting sample size was $N=1,459$ (71.4\% females), the age is ranged between 18 and 88 years, $M=34.35$, $S D=14.04$. Exclusion criteria were an age younger than 18 years, unrealistic or missing values as well as not having completed the sections needed for this analysis. Demographic data are depicted in Table 1. An indication of the e-mail address for future 


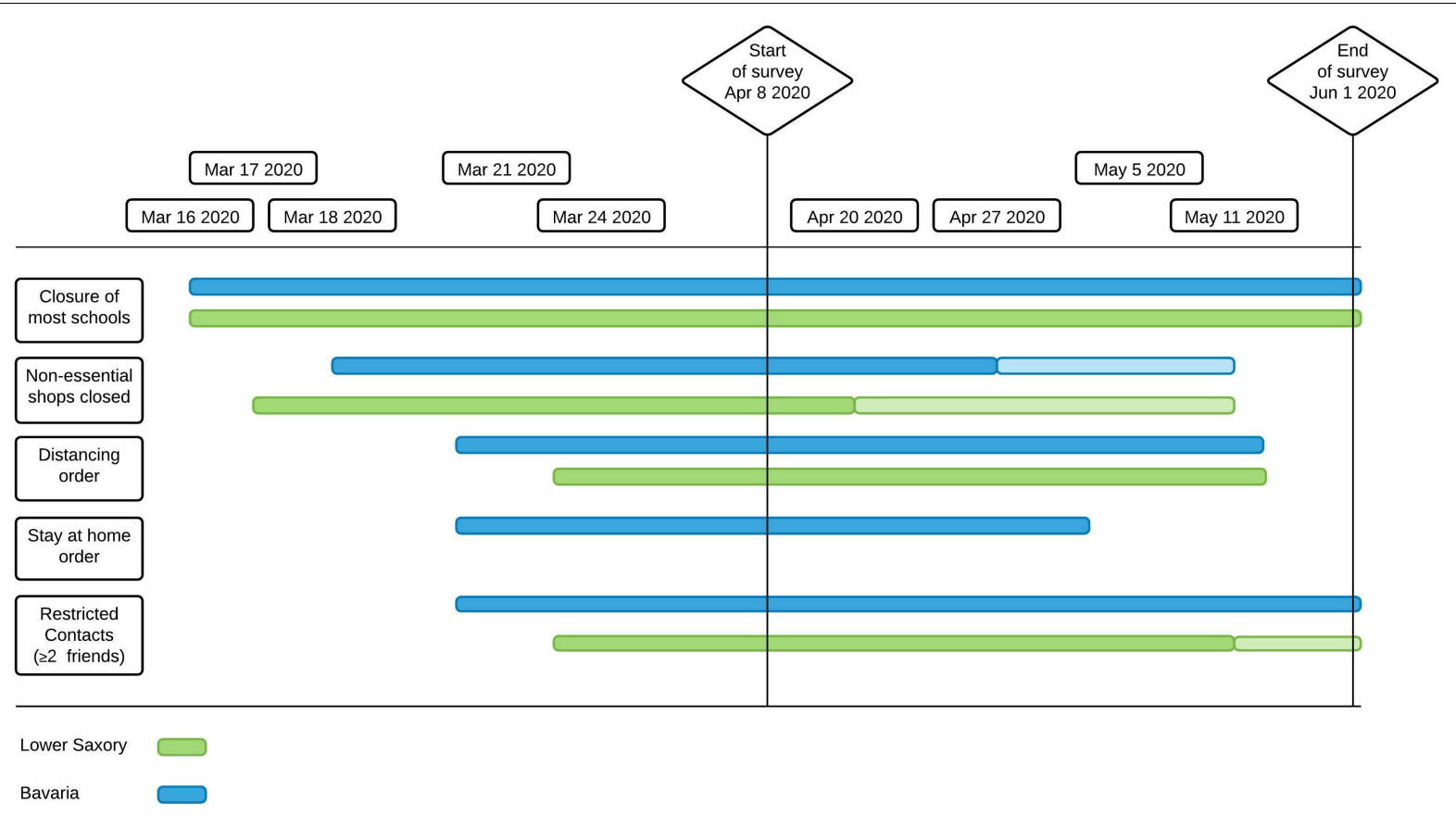

FIGURE 1 | Timeline for restrictions in Lower Saxony and Bavaria. Closure of most schools = Some classes with special priorities could still attend school (e.g., graduating classes); Stay at home order = People are not allowed to leave the house except for work, shopping essentials or walking/jogging alone. At the beginning of June 2020, in Bavaria social contacts were still restricted by order (less than 2 contacts allowed), whereas in Lower Saxony there was only a recommendation.

investigations was voluntary, otherwise no further personally identifiable information was collected. All participants gave their informed consent for participation and completed the questionnaires electronically. Data was collected anonymously without IP addresses or GPS tracking. Email address, when provided, was separated from the rest of the dataset. The study was approved by the Ethics Committee of the Department of Psychology at the PFH - Private University of Applied Sciences (Ethics application number: 251982).

\section{Reference Sample}

For standardization of the ISR questionnaire, which is described in the measures section, Tritt et al. (2010) used a sample of $n=8,892$ in-patients and of $n=2,512$ non-clinical subsample from all over Germany. Therefore, the non-clinical subsample is comparable to our sample as it has also been recruited throughout Germany. For this reason, we used it in the subsequent analysis and will refer to it as the "reference sample ". In contrast to our sample, the participants of Tritt et al. (2010) did not undergo any kind of contact restrictions or other pandemic measurements.

\section{Data Reduction: Subsamples}

To answer distinct research questions, two subsamples were used: The full sample consisted of 417 male and 1,042 female participants. We first matched our data to the existing reference sample (Tritt et al., 2010) in order to understand the magnitude of psychological burden in our data as a whole. In order to compare our data to a reference sample, 458 female participants were randomly selected to adapt the gender distribution of our sample to the reference sample, resulting in a subsample of $n=875$ participants ( $52.3 \%$ female). For comparing states with different lockdown measures, we only analysed data from participants living in Bavaria and Lower Saxony and excluded participants who lived outside the two target states, yielding a total of 777 complete data sets. The sampling procedure is depicted in Figure 2.

\section{Measures}

\section{Depressive Symptoms and Mental Health}

Depression and other mental health symptoms were both measured with the respective subscale of the self-report questionnaire ICD-10-Symptom-Rating [ISR, Tritt et al. (2008)] that can be used for clinical diagnostics in the German-speaking area. The ISR was designed and validated for the rapid assessment of depression, anxiety, eating disorder, obsessive compulsive disorder, and somatoform disorder symptoms. In total, the ISR contains 29 items to be rated on a 5-point-Likert-scale from 0 to 4 , with 0 indicating "does not apply" and 4 indicating "extremely applies." The period under consideration is the last 2 weeks. Subscales consist of either three (eating disorder subscale: e.g., "I spend a lot of time thinking of ways to lose weight") or four items (e.g., depression subscale: e.g., "I feel down and depressed"). There are also supplementary items (12 items) focusing on other ICD classifications, that are not included in the above categories. Furthermore, we added three items measuring reported differences in substance consumption. The ISR item scores are averaged for each subscale and the subscales can be taken together in a total score. The average of the response values of a category provides the score for each individual 
TABLE 1 | Demographics of total survey sample and resampled survey sample.

\begin{tabular}{|c|c|c|c|c|}
\hline \multirow[t]{2}{*}{ Variable } & \multicolumn{2}{|c|}{$\begin{array}{c}\text { Total } \\
\text { survey sample }\end{array}$} & \multicolumn{2}{|c|}{$\begin{array}{c}\text { Resampled } \\
\text { survey sample }\end{array}$} \\
\hline & $n$ & $\%$ & $n$ & $\%$ \\
\hline Total & 1459 & 100 & 875 & 100 \\
\hline \multicolumn{5}{|l|}{ Gender } \\
\hline Male & 417 & 28.6 & 417 & 47.7 \\
\hline Female & 1042 & 71.4 & 458 & 52.3 \\
\hline \multicolumn{5}{|l|}{ Marital Status } \\
\hline Single & 886 & 60.7 & 555 & 63.4 \\
\hline Married & 477 & 32.7 & 264 & 30.2 \\
\hline Widowed & 22 & 1.5 & 13 & 1.5 \\
\hline Separated & 74 & 5.1 & 43 & 4.9 \\
\hline \multicolumn{5}{|l|}{ Living Situation } \\
\hline Alone & 205 & 14.0 & 124 & 14.2 \\
\hline Shared Flat & 176 & 12.1 & 108 & 12.3 \\
\hline With partner & 426 & 29.2 & 256 & 29.3 \\
\hline With family & 652 & 44.7 & 387 & 44.2 \\
\hline \multicolumn{5}{|l|}{ Job Status during lockdown } \\
\hline Attending work as usual & 390 & 26.7 & 246 & 28.1 \\
\hline Attending work in home-office & 481 & 33.0 & 293 & 33.5 \\
\hline Mixture & 323 & 22.1 & 190 & 21.7 \\
\hline Not working & 143 & 9.8 & 86 & 9.8 \\
\hline Question does not apply to situation & 122 & 8.4 & 60 & 6.9 \\
\hline \multicolumn{5}{|l|}{ Living Area } \\
\hline Urban & 604 & 41.4 & 380 & 43.4 \\
\hline Rural & 855 & 58.6 & 495 & 56.6 \\
\hline COVID-19 diagnosis & 10 & 0.7 & 6 & 0.7 \\
\hline COVID-19 diagnosis in friends/family & 439 & 30.1 & 259 & 29.6 \\
\hline Quarantined & 85 & 5.8 & 48 & 5.5 \\
\hline
\end{tabular}

subscale, which is categorized according to severity. For instance, symptomatology of depression was considered suspicious, mild, moderate or severe if the respective average score was $\geq 0.75$, $\geq 1.0, \geq 2.0$ or $\geq 3.0$. The reported internal consistency for the total score is very good (Cronbach's $\alpha=0.92$ ) with slightly lower scores for the subscales (Cronbach's $\alpha=0.78-0.86$ ). The strengths of the ISR is its brevity and its pragmatic approach to good quality criteria, with validated scales: The ISR has shown good associations to other validated diagnostic tools such as the PHQ-D [German version of "PRIME MD Brief Patient Health Questionnaire," Löwe et al. (2002)] and with the widely used symptom Checklist-90 R [SCL-90; Franke and Derogatis (2002)] and has been validated in clinical samples (e.g., Brandt et al., 2015). In our sample, we calculated Cronbach's $\alpha$ for the depression subscale $(\alpha=0.81)$, the anxiety subscale $(\alpha=0.85)$, the compulsion subscale ( $\alpha=0.83$ ), the somatization subscale $(\alpha=0.83)$ and the eating disorder subscale $(\alpha=0.81)$.

\section{Lockdown Severity}

To compare different degrees of severity of the measures taken, we compared the data gained from the federal German states of Lower Saxony and Bavaria, as both states had enforced lockdown measures differing in severity (see Figure 1), based on the lockdown measures dataset from Steinmetz et al. (2020). In Bavaria, obligatory restrictive curfew was imposed starting from 21th of March until the beginning of May: People were only allowed to leave their houses to take care of the absolutely necessary (e.g., in certain cases going to work, doing sports on their own, grocery shopping and attending to home care services). In Lower Saxony, starting from 23rd of March, social distancing was recommended and enforced, however, citizens were only advised to voluntarily stay at home if possible.

\section{Statistical Analysis}

The subsequent analysis focused on comparing our sample and the reference sample. When comparing means between independent groups we calculated Welch's $t$-tests, due to inhomogeneity of variance between samples. As a measure for effect size, we used Hedge's $g$ due to a large difference in sample size. Furthermore, for depressive symptoms, we explored differences between male and female participants, age groups and states. In a series of hierarchical regression models, combinations

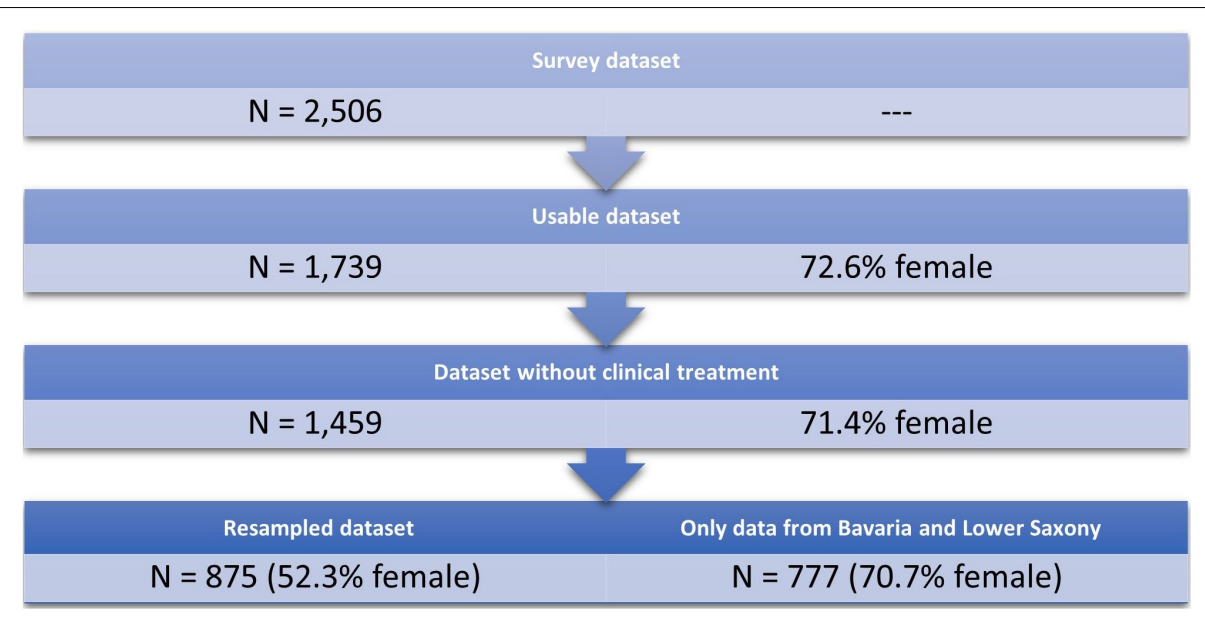

FIGURE 2 | Resampling procedure. From the remaining 1459 participants, 875 were resampled in order to balance the gender distribution. 
of age, gender and state were used to predict the average score of depression, compulsion, anxiety, eating disorder and somatization symptoms. To correct for multiple comparisons where appropriate, the false discovery rate [FDR, Benjamini and Hochberg (1995)] was applied. Reported $p$-values reflect the FDR correction. The statistical analysis was carried out using $\mathrm{R}$ 3.6.2 (R Core Team, 2017).

\section{RESULTS}

\section{Specific Symptoms}

The items with the highest mean scores in the survey sample were "I feel down and depressed" $(M=1.25, S D=1.04)$ for the depression subscale, "I try to avoid these harmless frightening situations" ( $M=0.76, S D=1.09)$ for the anxiety subscale, "I try to resist recurring, seemingly senseless thoughts and actions, but often don't succeed" $(M=0.54, S D=1.00)$ for the compulsion subscale, "I worry about having a serious physical illness" $(M=0.37, S D=0.80)$ for the somatization subscale and "I spend a lot of time thinking of ways to lose weight" $(M=0.90$, $S D=1.21$ ) for the eating disorder subscale.

\section{Comparison of the COVID-19 Sample With the Reference Sample}

We found significant differences between the reference and the COVID-19 sample in depressive symptoms, compulsive symptoms and symptoms of eating disorder, as displayed in Table 2 and Figure 3, with higher burden in the COVID-19 sample. We found no different scores on the anxiety scale and a very small difference in somatization symptoms with higher prevalence in the reference sample (see Table 2). Significant medium effects for depressive disorder and significant but small effects for compulsive, eating disorder and somatization symptoms were found.

\section{Gender, Age and State of Residence and ISR Symptom Severity}

We calculated linear regression models for each of the ISR symptom scales $(N=1,459$; see Table 3 and Figure 4). For each subscale, we compared models that only considered main effects to models that included an interaction term. Except for the eating disorder subscale, we found that the added interaction term was neither a significant predictor nor did it improve the model fits. In all subscales except somatization, age was a significant predictor. For instance, for every additional year in participants' age, the depression score decreased by 0.012 points. Similarly, male participants reported less severe symptoms than female participants (again, except for somatization). We then correlated the subscales against each other (Figure 5). Except for the eating disorder subscale, all subscales were significantly correlated to at least one other subscale, with the compulsion and anxiety subscale showing the strongest correlation.

\section{State of Residence}

There were no significant differences in average symptom severity for depression, compulsion, anxiety, somatization or eating disorder symptoms between Lower Saxony and Bavaria (all $p>0.155)$. Average male scores were at $M=0.79(S D=0.72)$ in Lower Saxony and $M=0.87(S D=0.80)$ in Bavaria, average female scores were $M=1.01(S D=0.90)$ in Lower Saxony and $M=0.90(S D=0.78)$ in Bavaria. For eating disorders, average scores were at $M=0.75(S D=1.00)$ in Lower Saxony and $M=0.76$ $(S D=1.03)$ in Bavaria. Average male scores were at $M=0.46$ $(S D=0.70)$ in Lower Saxony and $M=0.53(S D=0.86)$ in Bavaria, average female scores were $M=0.88(S D=1.08)$ in Lower Saxony and $M=0.85(S D=1.08)$ in Bavaria. Means and standard deviations can be found in Table 4.

\section{DISCUSSION}

The aim of this study was to contribute to a deeper understanding of the psychological burden associated with restrictions taken by German federal state governments as a consequence of the COVID-19 pandemic with a specific focus on depressive symptoms. By providing information concerning psychological well-being during a period of unprecedented conditions (COVID-19, lockdown measures), we aimed to support an informational base for the development of prevention and recovery action. In comparison with reference data (Tritt et al., 2010) from prior to the current outbreak, as expected, our results suggest a high prevalence of depressive symptoms, but also

TABLE 2 | Mean and Standard Deviation of ISR subscale scores for reference sample and survey sample.

\begin{tabular}{|c|c|c|c|c|c|c|}
\hline \multirow[b]{3}{*}{ ISR Scales } & \multicolumn{2}{|c|}{ Sample } & \multirow[b]{3}{*}{$d f$} & \multirow[b]{3}{*}{$t$} & \multirow[b]{3}{*}{$p$} & \multirow{3}{*}{$\begin{array}{c}\text { Effect size } \\
g\end{array}$} \\
\hline & Reference sample $(N=2512)$ & Survey sample $(N=875)$ & & & & \\
\hline & $M(S D)$ & $M(S D)$ & & & & \\
\hline Depression & $0.54(0.69)$ & $0.91(0.83)$ & 1318 & 11.84 & $0.006^{\star \star}$ & 0.51 \\
\hline Anxiety & $0.45(0.66)$ & $0.46(0.77)$ & 1348 & 0.34 & 0.732 & 0.01 \\
\hline Compulsion & $0.32(0.57)$ & $0.47(0.81)$ & 1189 & 5.06 & $0.003^{\star \star}$ & 0.23 \\
\hline Eating disorder & $0.52(0.76)$ & $0.71(0.95)$ & 1285 & 5.35 & $0.002^{\star \star}$ & 0.23 \\
\hline Somatization & $0.35(0.60)$ & $0.27(0.64)$ & 1444 & -3.24 & $0.001^{* \star}$ & 0.13 \\
\hline Sum & $0.40(0.45)$ & $0.53(0.55)$ & 1304 & 6.30 & $0.001^{\star \star}$ & 0.27 \\
\hline
\end{tabular}

Means (M) and standard deviations (SDs) for the ISR subscales; $p=$ adjusted significance $(\alpha<0.05)$; ** indicates $p<0.01$; effect sizes are reported as Hedge's g. 


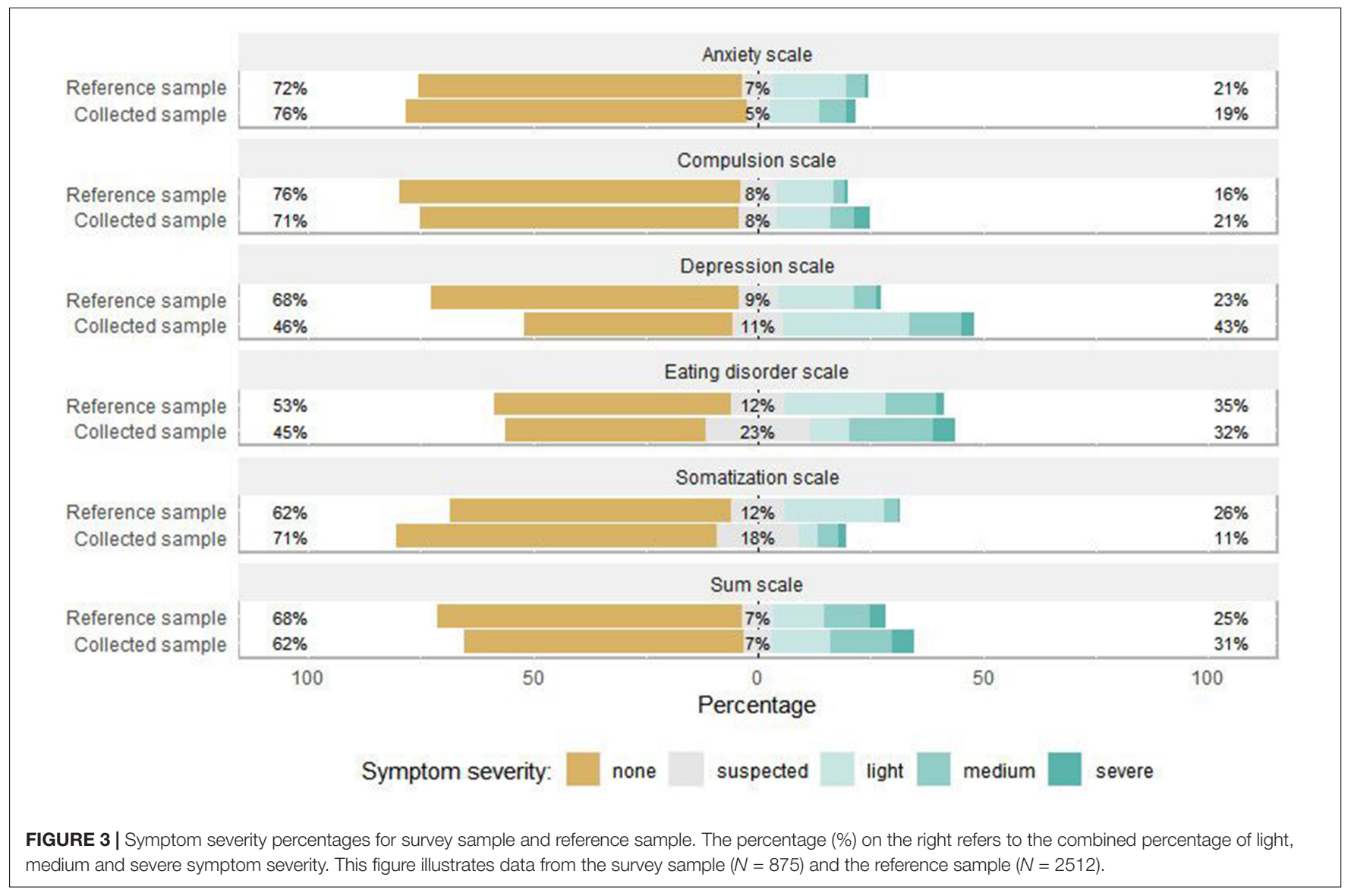

TABLE 3 | Results of linear regression models with age and gender predicting ISR sub-scales.

\begin{tabular}{|c|c|c|c|c|c|c|}
\hline ISR Scale & Predictor & Estimate & SEM & $\mathbf{t}$ & $p$ & $\mathbf{R}^{2}$ \\
\hline & Gender * & -0.283 & 0.121 & -2.339 & 0.019 & \\
\hline & Gender * & -0.183 & 0.045 & -4.072 & $<0.001$ & \\
\hline \multirow[t]{2}{*}{ Compulsion } & Age & -0.009 & 0.001 & -6.171 & $<0.001$ & 0.029 \\
\hline & Gender * & 0.109 & 0.046 & -2.353 & 0.018 & \\
\hline & Gender * & -0.012 & 0.034 & -0.367 & 0.713 & \\
\hline \multirow[t]{3}{*}{ Eating disorder ** } & Age & -0.011 & 0.002 & -5.61 & $<0.001$ & 0.041 \\
\hline & Gender * & -0.649 & 0.141 & -4.608 & $<0.001$ & \\
\hline & Age $\times$ Gender & 0.009 & 0.003 & 2.692 & $<0.01$ & \\
\hline
\end{tabular}

${ }^{*}$ Gender dummy coded to female $=0$ and male $=1 ;{ }^{* *}$ Model fit $(\mathrm{AlC})$ increased significantly by adding the interaction term, $F(1,1455)=7.245, p<0.01$.

of compulsory and eating disorder symptoms. It appears that the prevalence of anxiety symptoms was the same in both samples, while the prevalence of somatization symptoms was higher in the reference sample.

\section{Findings on Symptom Prevalence}

A general increase in the rates of depressive symptoms during a pandemic would be in line with previous studies conducted before the coronavirus outbreak (Hawryluck et al., 2004; Yip et al., 2010; Brooks et al., 2020) and with other prevalence studies conducted during the COVID-19 pandemic (Bäuerle et al., 2020b; Pieh et al., 2020; Rossi et al., 2020; Wang et al., 2021) as well as longitudinal studies (Castellini et al., 2021). With regard to our exploratory findings, starting with eating disorder symptoms, two studies investigating reactions of formerly diagnosed patients also reported worsening of eating disorder symptoms during lockdown in European samples (Fernández-Aranda et al., 2020; Robertson et al., 2021), studies targeting eating disorder symptoms in the general population during the COVID-19 crisis are still scarce to our knowledge: 

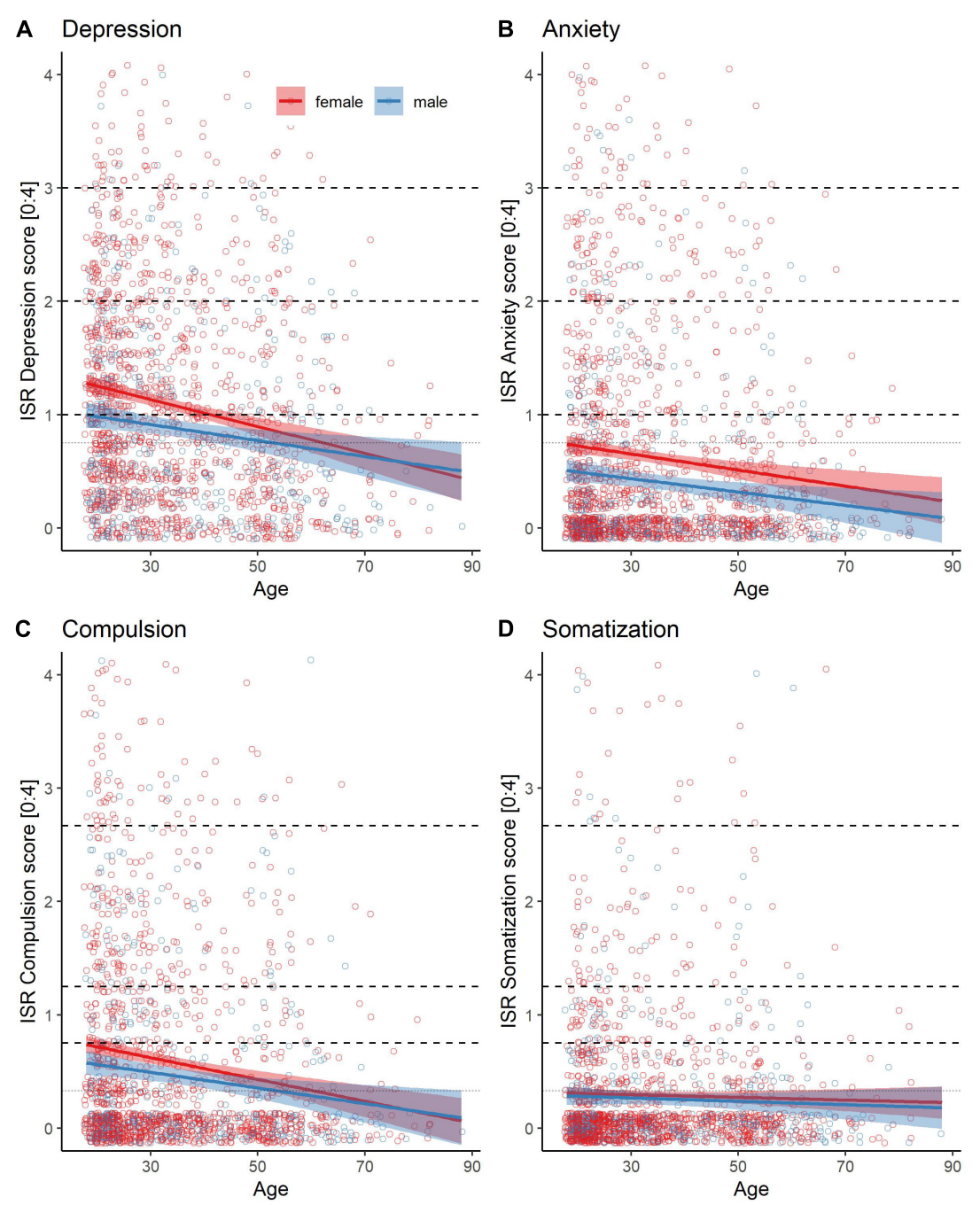

E Eating disorder

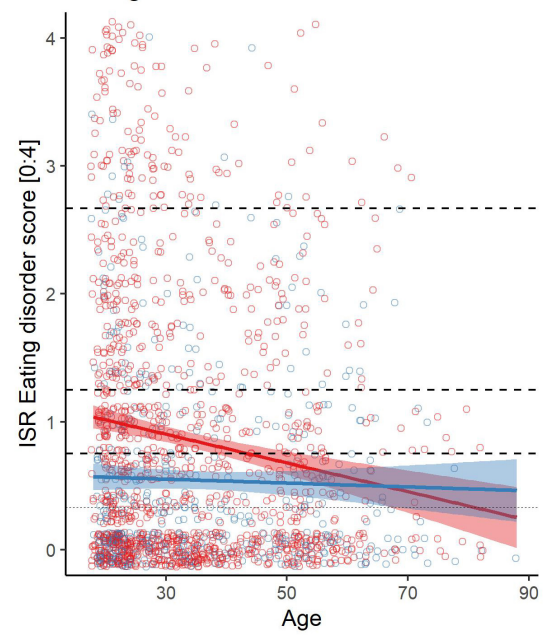

FIGURE 4 | Subscale scores as a function of age and gender. Solid lines represent linear model and shaded areas confidence intervals for the subscales (A) Depression, (B) Anxiety, (C) Compulsion, (D) Somatization, and (E) Eating Disorder. The dashed horizontal lines represent cut-offs of symptom severity, increasing from bottom to top in mild, moderate and severe symptom levels. 


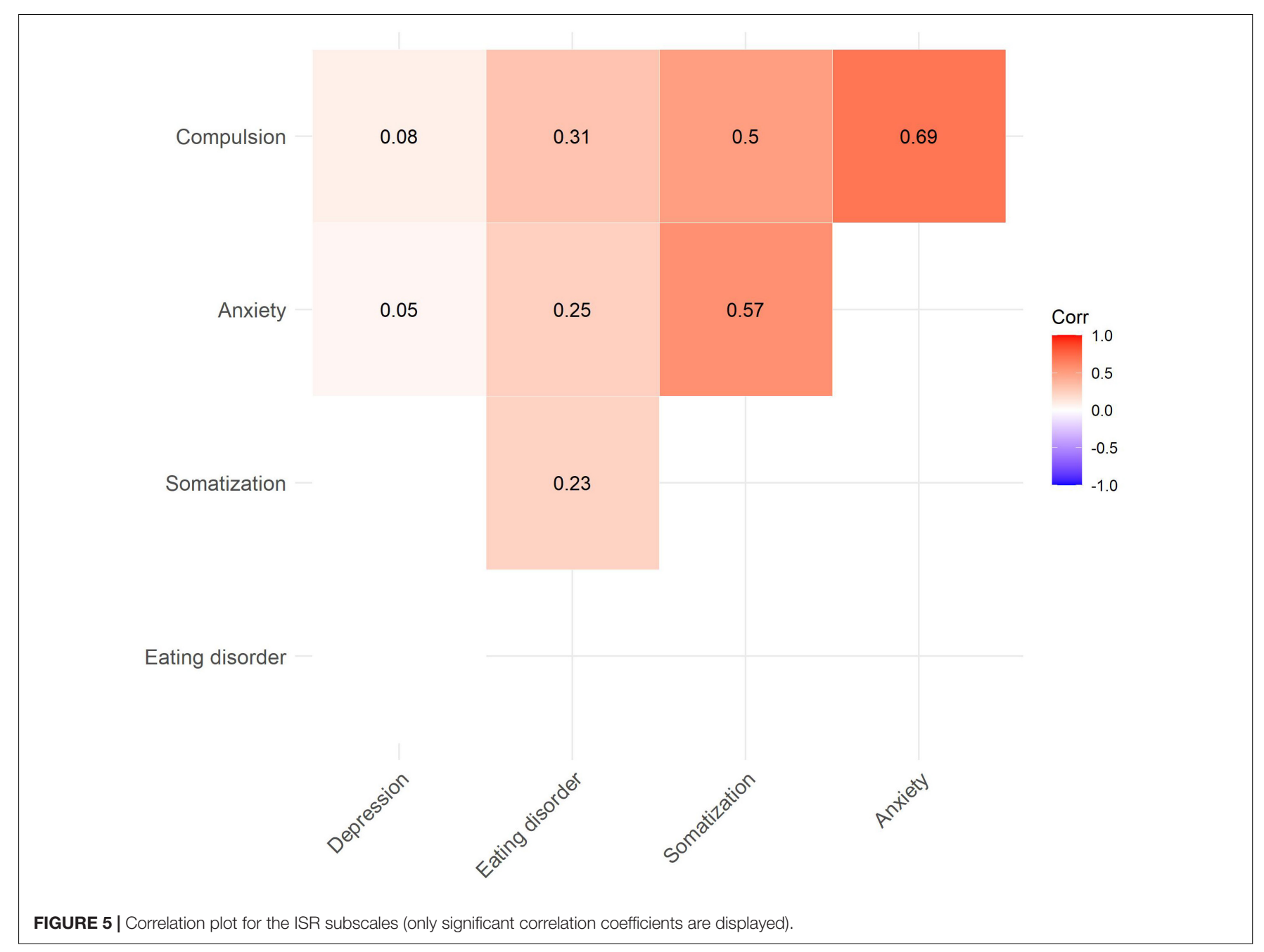

One Australian study showed an increase in restricting and binge eating behaviors (Phillipou et al., 2020). Furthermore, increases in unhealthy eating behavior became apparent: One study conducted in Italy found a weight gain in $48.6 \%$ of the population (Di Renzo et al., 2020) and an international online survey found decreases in physical activity and more unhealthy food consumption patterns (Ammar et al., 2020). There are not many studies with a focus on compulsive symptoms, however, in former patients (Jelinek et al., 2021) as well as adolescents and children (Tanir et al., 2020), increases in symptomatology have been documented. Interestingly, our study did not find elevated anxiety symptoms, which is contradictory to the results of, e.g., Li et al. (2020) and Zhu et al. (2020). However, other studies also showed no increase in anxiety symptoms in China (e.g., Wang et al., 2020) and in a longitudinal study in the Netherlands (Pan et al., 2021). Higher anxiety levels have been shown to be related to lower social capital (Xiao et al., 2020), to poor mental health (Wang et al., 2021) and to COVID-19-infections (Özdin and Bayrak Özdin, 2020) while living in urban areas and a steady family income served as protection from elevated anxiety levels (Cao et al., 2020). As most people in Germany have comparably high financial security, the degree of COVID-19-infections in our sample was low and only mentally healthy participants were included in this study, our sample might therefore not have been very vulnerable to experience anxiety. Most surprising was the low prevalence of somatization symptoms. When looking at the intercorrelations of the scales, it was interesting to note that this study showed low associations between the depressive subscale and the other scales, where other studies show high associations (e.g., Olfson et al., 2017). However, one study recently demonstrated that there are specific risk factors, not only predicting elevated psychopathological symptoms during the COVID-19 pandemic, but also comorbidities (Palgi et al., 2020). This study showed that loneliness predicted the comorbidity between anxiety and depressive symptoms. Furthermore, one could assume, that the increase in depressive symptoms was a normal rather than a psychopathological reaction to a loss of incentives, social support, ease of life, and very specific to the restrictions following the COVID-19 pandemic and therefore not associated with other psychopathologies.

\section{Findings on Symptom Predictors}

Regarding gender and age, some differences in the rates and severity of psychological burden were found: Females showed 
TABLE 4 | ISR subscales and total scores for all samples, separated by gender.

\begin{tabular}{|c|c|c|c|c|c|c|c|c|}
\hline \multirow[t]{3}{*}{ Variable } & \multirow{2}{*}{\multicolumn{2}{|c|}{$\begin{array}{l}\text { Survey sample (resampled) } \\
\qquad N=875\end{array}$}} & \multirow{2}{*}{\multicolumn{2}{|c|}{$\begin{array}{c}\text { Reference sample } \\
\qquad N=2512\end{array}$}} & \multirow{2}{*}{\multicolumn{2}{|c|}{$\begin{array}{c}\text { Bavarian sample } \\
\qquad N=276\end{array}$}} & \multirow{2}{*}{\multicolumn{2}{|c|}{$\begin{array}{l}\text { Lower Saxony sample } \\
\qquad N=501\end{array}$}} \\
\hline & & & & & & & & \\
\hline & $M$ & $S D$ & $M$ & $S D$ & $M$ & $S D$ & $M$ & $S D$ \\
\hline Depression scores & 0.91 & 0.83 & 0.54 & 0.69 & 0.89 & 0.78 & 0.93 & 0.85 \\
\hline Male & 0.81 & 0.78 & - & - & 0.87 & 0.80 & 0.79 & 0.72 \\
\hline Female & 1.00 & 0.87 & - & - & 0.90 & 0.78 & 1.01 & 0.90 \\
\hline Compulsion scores & 0.47 & 0.81 & 0.32 & 0.57 & 0.41 & 0.78 & 0.51 & 0.84 \\
\hline Male & 0.39 & 0.72 & - & - & 0.39 & 0.76 & 0.42 & 0.71 \\
\hline Female & 0.55 & 0.88 & - & - & 0.42 & 0.79 & 0.56 & 0.89 \\
\hline Anxiety scores & 0.46 & 0.77 & 0.45 & 0.66 & 0.37 & 0.63 & 0.49 & 0.79 \\
\hline Male & 0.34 & 0.63 & - & - & 0.30 & 0.53 & 0.35 & 0.57 \\
\hline Female & 0.57 & 0.86 & - & - & 0.40 & 0.66 & 0.56 & 0.87 \\
\hline Somatization scores & 0.27 & 0.64 & 0.35 & 0.60 & 0.24 & 0.57 & 0.26 & 0.61 \\
\hline Male & 0.25 & 0.59 & - & - & 0.24 & 0.63 & 0.24 & 0.51 \\
\hline female & 0.29 & 0.68 & - & - & 0.25 & 0.55 & 0.27 & 0.65 \\
\hline Eating disorder scores & 0.71 & 0.95 & 0.52 & 0.76 & 0.76 & 1.03 & 0.75 & 1.00 \\
\hline Male & 0.52 & 0.75 & - & - & 0.53 & 0.86 & 0.46 & 0.70 \\
\hline Female & 0.88 & 1.07 & - & - & 0.85 & 1.08 & 0.88 & 1.08 \\
\hline Sum scores & 0.53 & 0.55 & 0.40 & 0.45 & 0.49 & 0.47 & 0.55 & 0.57 \\
\hline Male & 0.45 & 0.49 & - & - & 0.44 & 0.43 & 0.44 & 0.45 \\
\hline Female & 0.60 & 0.59 & - & - & 0.51 & 0.48 & 0.60 & 0.60 \\
\hline
\end{tabular}

Means (M) and Standard Deviations (SDs) of the ISR subscale scores and total score. For the reference sample, gender-specific values were not available.

higher rates of all scales except for somatization, which was not surprising considering that the general risk of those disorders is higher for this group (Sepulveda et al., 2008; Busch et al., 2013; Grobe et al., 2018). Females might also be especially vulnerable during the COVID-19 pandemic because they often tend to work in fields that were most affected by the pandemic, they are also more likely to be responsible for childcare which might increase worrying behaviors (Alon et al., 2020; Niedzwiedz et al., 2021). Furthermore, lockdown increased risks of domestic violence, which usually affects women more often (Alon et al., 2020).

Our results suggest, that younger people have higher symptoms in all symptom subscales than older participants, except for the somatization scale. This supports previous findings (Bäuerle et al., 2020b; Pieh et al., 2020) that mental health of young adults and women was significantly more burdened by the COVID-19 pandemic and the lockdown. One explanation could be that older people often have better emotion regulation skills (Charles, 2010) that help coping with the psychological effects of the pandemic (Barber and Kim, 2021). Results from this study showed that older men exhibited less worrying related to the Corona pandemic. Pieh et al. (2020) assumed that younger people are usually more likely to experience job insecurity and financial problems, the lockdown and the resulting restrictions might therefore have a greater impact on the daily lives of younger adults. It is important to note, that, although significant, these were small effects and our model could only explain $4 \%$ of variance.

Contrary to other studies (e.g., Benke et al., 2020), no difference in symptomatology was found between people living in Lower Saxony and Bavaria even though Bavaria had a stay-at-home order and Lower Saxony did not. This result, however, is consistent with data collected conducted prior to the pandemic, where no significant difference in prevalence rates for depression in adults was found between these two states regardless of gender (Bretschneider et al., 2017). Therefore, it can be concluded that a voluntary stay-at-home order in comparison with a forced stay-at-home order did not have an impact on differences in mental health symptoms in our sample.

\section{Limitations}

There are several limitations to this study. First, any observations made here are purely correlational. There were neither baseline measures nor any follow-up measures conducted and therefore no statements about the development of symptoms or long-term effects can yet be made. Second, the data presented here was collected from a convenience sample. Therefore, even despite our resampling efforts, the sample reported on here, likely differs from the reference sample (Tritt et al., 2010). As the study was mainly conducted with residents of Lower Saxony and Bavaria, it is unclear if the data can be generalized to Germany's population as a whole. In addition, the reference sample used to establish differences in symptom rates, is ten years old (Tritt et al., 2010). Since then, an increase in depressive disorders is likely, as incidence rates for depressive disorders in Germany have increased (see Kaufmännische Krankenkasse., 2020, May 25). Our study therefore cannot clearly state whether the high symptom prevalence is due to the restrictions or due to a general increase in symptoms during the last decade. Second, despite the described differences in lockdown measures 
between the two German states, in both states restrictions were imposed. Therefore, the study can mainly make the specific point that a forced stay-at-home order did not have an impact on psychological burden compared to a voluntary stay-athome order.

\section{Implications}

Still, the results of this study complement the results of other research during the first weeks after restrictions: It matches the results of comparable studies in other countries in terms of depressive symptoms (e.g., Pieh et al., 2020) and provides interesting new results concerning high prevalence of eating disorder and compulsive symptoms, especially for younger and female adults. As the ISR has been validated with a large sample size and shows good quality criteria, it serves as a good measure of psychological burden, so the data here can be considered as a screening. The current study could therefore be interpreted as a warning sign. The duration and causes of psychological burden should be further investigated, and countermeasures should be taken. In a nationwide lockdown, online mental health counseling is a far-reaching method to help many people (Dan, 2020). One helpful prevention measure is to educate the public on what mental health issues they may face during times of isolation. It is useful to provide tips on how people can handle individual situations and suffering, such as loneliness, in order to manage these situations and minimize suffering (Hiremath et al., 2020). Tele-mental-health services, online platforms and social media are helpful for support and care during mental health crises in the Corona pandemic, especially in rural areas (Zhou et al., 2020). For instance, the e-mental health intervention 'CoPE It' is a low-threshold approach to support people with mental distress during the Corona pandemic (Bäuerle et al., 2020a). In Wuhan, a free psychological counseling service was offered online to reduce people's distress (Dan, 2020). Employers in Canada supported their employees by dropping mental health fees, providing support and educating them about mental health (Ho et al., 2020). Furthermore, various online mental health services can be taken as preventive measures to identify atrisk groups (Liu et al., 2020). Still, for those developing mental

\section{REFERENCES}

Alon, T., Doepke, M., Olmstead-Rumsey, J., and Tertilt, M. (2020). The impact of covid-19 on gender equality. National Bureau of Economic Research doi: 10.3386/w26947 Epub ahead of print.

Ammar, A., Brach, M., Trabelsi, K., Chtourou, H., Boukhris, O., Masmoudi, L., et al. (2020). Effects of COVID-19 home confinement on eating behaviour and physical activity: results of the ECLB-COVID19 international online survey. Nutrients 12:1583. doi: 10.3390/nu12061583

Barber, S. J., and Kim, H. (2021). Covid-19 worries and behavior changes in older and younger men and women. J. Gerontol. B Psychol. Sci. Soc. Sci. 76, e17-e23. doi: 10.1093/geronb/gbaa068

Bartoszek, A., Walkowiak, D., Bartoszek, A., and Kardas, G. (2020). Mental wellbeing (depression, loneliness, insomnia, daily life fatigue) during COVID-19 related home-confinement-a study from Poland. Int. J. Environ. Res. Public Health 17:7417. doi: 10.3390/ijerph17207417

Bäuerle, A., Graf, J., Jansen, C., Musche, V., Schweda, A., Hetkamp, M., et al. (2020a). E-mental health mindfulness-based and skills-based 'CoPE It' intervention to reduce psychological distress in times of COVID-19: study disorders face-to-face therapies should be available. Sports (Pieh et al., 2020) as well as pursuing new projects or hobbies at home (de Quervain et al., 2020) seemed to function as resilience factors.

\section{CONCLUSION}

Even though this study provides merely a snapshot, due to a relatively large sample size, this dataset can contribute to a better overview of the psychological burden on mentally healthy participants during the COVID-19 pandemic in parts of Germany. We conclude that the prevalence of several symptoms, among them eating disorder and compulsion symptoms, but especially depressive symptoms in our sample was high during the first weeks after the restrictions in Germany. While the level of restrictiveness had no impact on mental health, young age and female gender seemed to slightly increase psychological burden.

\section{DATA AVAILABILITY STATEMENT}

The datasets generated for this study are available on request to the corresponding author.

\section{ETHICS STATEMENT}

The study was approved by the Ethics Committee of the Department of Psychology at the PFH - Private University of Applied Science, Göttingen (Ethics application number: 251982). The patients/participants provided their written informed consent to participate in this study.

\section{AUTHOR CONTRIBUTIONS}

IS, MK, and YS: concept, manuscript, and data. AE, SS, and RL: concept and manuscript. ML: data and manuscript. SR and TT: data. JB and MM: manuscript. All authors contributed to the article and approved the submitted version.

protocol for a bicentre longitudinal study. BMJ Open 10:e039646. doi: 10.1136/ bmjopen-2020-039646

Bäuerle, A., Teufel, M., Musche, V., Weismüller, B., Kohler, H., Hetkamp, M., et al. (2020b). Increased generalized anxiety, depression and distress during the COVID-19 pandemic: a cross-sectional study in Germany. J. Public Health 42, 672-678. doi: 10.1093/pubmed/fdaa106

Benjamini, Y., and Hochberg, Y. (1995). Controlling the false discovery rate: a practical and powerful approach to multiple testing. J. R. Stat. Soc. Ser. B 57, 289-300. doi: 10.1111/j.2517-6161.1995.tb02031.x

Benke, C., Autenrieth, L. K., Asselmann, E., and Pané-Farré, C. A. (2020) Lockdown, quarantine measures, and social distancing: associations with depression, anxiety and distress at the beginning of the COVID-19 pandemic among adults from Germany. Psychiatry Res. 293:113462. doi: 10.1016/j. psychres.2020.113462

Brandt, W. A., Loew, T., Heymann, F., von, Stadtmüller, G., Georgi, A., Tischinger, M., et al. (2015). Das ICD-10 Symptomrating (ISR): Validierung der Depressionsskala an einer klinischen Stichprobe [The ICD-10 Symptom Rating (ISR): validation of the depression scale in a clinical sample]. Psychother. Psychosom. Med. Psychol. 65, 234-237. doi: 10.1055/s-0034- 1398542 
Bretschneider, J., Kuhnert, R., and Hapke, U. (2017). Depressive symptoms among adults in Germany. J. Health Monit. 2, 77-83.

Brooks, S. K., Webster, R. K., Smith, L. E., Woodland, L., Wessely, S., Greenberg, N., et al. (2020). The psychological impact of quarantine and how to reduce it: rapid review of the evidence. Lancet 395, 912-920. doi: 10.1016/S0140-6736(20) 30460-8

Busch, M., Maske, U., Ryl, L., Schlack, R., and Hapke, U. (2013). Prevalence of depressive symptoms and diagnosed depression among adults in Germany: results of the German Health Interview and Examination Survey for Adults (DEGS1)]. Bundesgesundheitsblatt Gesundheitsforschung Gesundheitsschutz 56, 733-739.

Cacioppo, J. T., Cacioppo, S., Capitanio, J. P., and Cole, S. W. (2015). The neuroendocrinology of social isolation. Ann. Rev. Psychol. 66, 733-767. doi: 10.1146/annurev-psych-010814-015240

Cao, W., Fang, Z., Hou, G., Han, M., Xu, X., Dong, J., et al. (2020). The psychological impact of the COVID-19 epidemic on college students in China. Psychiatry Res. 287:112934. doi: 10.1016/j.psychres.2020.112934

Castellini, G., Rossi, E., Cassioli, E., Sanfilippo, G., Innocenti, M., Gironi, V., et al. (2021). A longitudinal observation of general psychopathology before the COVID-19 outbreak and during lockdown in Italy. J. Psychosom. Res. 141:110328. doi: 10.1016/j.jpsychores.2020.110328

Charles, S. T. (2010). Strength and vulnerability integration: a model of emotional well-being across adulthood. Psychol. Bull. 136, 1068-1091. doi: 10.1037/ a0021232

Conradi, H. J., Noordhof, A., and Arntz, A. (2020). Improvement of conflict handling: hand-holding during and after conflict discussions affects heart rate, mood, and observed communication behavior in romantic partners. J. Sex Marital Ther. 46, 419-434. doi: 10.1080/0092623X.2020.1748778

Dan, Z. (2020). China adopts non-contact free consultation to help the public cope with the psychological pressure caused by new coronavirus pneumonia. Asian J. Psychiatr. 52:102093. doi: 10.1016/j.ajp.2020.102093

de Quervain, D., Aerni, A., Amini, E., Bentz, D., Coynel, D., Gerhards, C., et al. (2020). The Swiss Corona Stress Study. [Preprint]. doi: 10.31219/osf.io/ jqw6a

Di Renzo, L., Gualtieri, P., Pivari, F., Soldati, L., Attinà, A., Cinelli, G., et al. (2020). Eating habits and lifestyle changes during COVID-19 lockdown: an Italian survey. J. Transl. Med. 18:229. doi: 10.1186/s12967-020-02399-5

Fernández-Aranda, F., Casas, M., Claes, L., Bryan, D. C., Favaro, A., Granero, R., et al. (2020). Covid-19 and implications for eating disorders. Eur. Eat. Disord. Rev. 28, 239-245. doi: 10.1002/erv.2738

Franke, G. H., and Derogatis, L. R. (2002). Symptom-Checkliste von LR Derogatis: SCL-90-R; deutsche Version. Göttingen: Beltz Test.

Grewen, K. M., Anderson, B. J., Girdler, S. S., and Light, K. C. (2003). Warm partner contact is related to lower cardiovascular reactivity. Behav. Med. 29, 123-130. doi: 10.1080/08964280309596065

Grobe, T. G., Kleine-Budde, K., Bramesfeld, A., Thom, J., Bretschneider, J., and Hapke, U. (2018). Prevalences of depression among adults: comparative analysis of a nationwide survey and routine data. Gesundheitswesen 81, 1011-1017.

Hawryluck, L., Gold, W. L., Robinson, S., Pogorski, S., Galea, S., and Styra, R. (2004). SARS control and psychological effects of quarantine, Toronto, Canada. Emerg. Infect. Dis. 10, 1206-1212. doi: 10.3201/eid1007.030703

Hiremath, P., Suhas Kowshik, C. S., Manjunath, M., and Shettar, M. (2020). Covid 19: impact of lock-down on mental health and tips to overcome. Asian J. Psychiatry 51:102088. doi: 10.1016/j.ajp.2020.102088

Ho, C. S., Chee, C. Y., and Ho, R. C. (2020). Mental health strategies to combat the psychological impact of COVID-19 beyond paranoia and panic. Ann. Acad. Med. Singap. 49, 155-160. doi: 10.47102/annals-acadmedsg.202043

Holt-Lunstad, J., Smith, T. B., Baker, M., Harris, T., and Stephenson, D. (2015). Loneliness and social isolation as risk factors for mortality: a meta-analytic review. Perspect. Psychol. Sci. 10, 227-237. doi: 10.1177/1745691614568352

Jelinek, L., Moritz, S., Miegel, F., and Voderholzer, U. (2021). Obsessivecompulsive disorder during COVID-19: turning a problem into an opportunity? J. Anxiety Disord. 77:102329. doi: 10.1016/j.janxdis.2020.102329

Kaufmännische Krankenkasse. (2020). Stress, Angst, Trauer: Immer mehr Menschen mit Depressionen. Available online at: https://www.kkh.de/ presse/pressemeldungen/stress-angst-trauer-immer-mehr-menschen-mitdepressionen (accessed May 28).
Li, S., Wang, Y., Xue, J., Zhao, N., and Zhu, T. (2020). The impact of COVID-19 epidemic declaration on psychological consequences: a study on active weibo users. Int. J. Environ. Res. Public Health 17:2032. doi: 10.3390/ijerph17062032

Liu, S., Yang, L., Zhang, C., Xiang, Y.-T., Liu, Z., Hu, S., et al. (2020). Online mental health services in China during the COVID-19 outbreak. Lancet Psychiatry 7, e17-e18. doi: 10.1016/S2215-0366(20)30077-8

Löwe, B., Zipfel, S., and Herzog, W. (2002). Deutsche Übersetzung und Validierung des Patient Health Questionnaire "(PHQ) von Spitzer, Kroenke und Williams. Heidelberg: Medizinische Universitätsklinik Heidelberg.

Niedzwiedz, C. L., Green, M. J., Benzeval, M., Campbell, D., Craig, P., Demou, E., et al. (2021). Mental health and health behaviours before and during the initial phase of the COVID-19 lockdown: longitudinal analyses of the UK Household Longitudinal Study. J. Epidemiology Community Health 75, 224-231. doi: 10. 1136/jech-2020-215060

Olfson, M., Mojtabai, R., Merikangas, K. R., Compton, W. M., Wang, S., Grant, B. F., et al. (2017). Reexamining associations between mania, depression, anxiety and substance use disorders: results from a prospective national cohort. Mol. Psychiatry 22, 235-241. doi: 10.1038/mp.2016.64

Özdin, S., and Bayrak Özdin, Ş (2020). Levels and predictors of anxiety, depression and health anxiety during COVID-19 pandemic in Turkish society: the importance of gender. Int. J. Soc. Psychiatry 66, 504-511. doi: 10.1177/ 0020764020927051

Palgi, Y., Shrira, A., Ring, L., Bodner, E., Avidor, S., Bergman, Y., et al. (2020). The loneliness pandemic: loneliness and other concomitants of depression, anxiety and their comorbidity during the COVID-19 outbreak. J. Affect. Disord. 275, 109-111. doi: 10.1016/j.jad.2020.06.036

Pan, K.-Y., Kok, A. A. L., Eikelenboom, M., Horsfall, M., Jörg, F., Luteijn, R. A., et al. (2021). The mental health impact of the COVID-19 pandemic on people with and without depressive, anxiety, or obsessive-compulsive disorders: a longitudinal study of three Dutch case-control cohorts. Lancet Psychiatry 8, 121-129. doi: 10.1016/S2215-0366(20)30491-0

Peters, A., Rospleszcz, S., Greiser, K. H., Dallavalle, M., and Berger, K. (2020). The Impact of the COVID-19 Pandemic on Self-Reported Health. Deutsches Arzteblatt International 117, 861-867. doi: 10.3238/arztebl.2020.0861

Petzold, M. B., Bendau, A., Plag, J., Pyrkosch, L., Mascarell Maricic, L., Betzler, F., et al. (2020). Risk, resilience, psychological distress, and anxiety at the beginning of the COVID-19 pandemic in Germany. Brain Behav. 10:e1745. doi: 10.1002/brb3.1745

Phillipou, A., Meyer, D., Neill, E., Tan, E. J., Toh, W. L., van Rheenen, T. E., et al. (2020). Eating and exercise behaviors in eating disorders and the general population during the COVID-19 pandemic in Australia: initial results from the COLLATE project. Int. J. Eat. Disord. 53, 1158-1165. doi: 10.1002/eat. 23317

Pieh, C., Budimir, S., and Probst, T. (2020). The effect of age, gender, income, work, and physical activity on mental health during coronavirus disease (COVID-19) lockdown in Austria. J. Psychosom. Res. 136:110186. doi: 10.1016/j.jpsychores. 2020.110186

R Core Team. (2017). R: A Language and Environment for Statistical Computing. Vienna, Austria: R Foundation for Statistical Computing.

Robertson, M., Duffy, F., Newman, E., Prieto Bravo, C., Ates, H. H., and Sharpe, H. (2021). Exploring changes in body image, eating and exercise during the COVID-19 lockdown: a UK survey. Appetite 159:105062. doi: 10.1016/j.appet. 2020.105062

Röhr, S., Reininghaus, U., and Riedel-Heller, S. G. (2020). Mental wellbeing in the German old age population largely unaltered during COVID-19 lockdown: results of a representative survey. BMC Geriatr. 20:489. doi: 10.1186/s12877020-01889-x

Rossi, R., Socci, V., Talevi, D., Mensi, S., Niolu, C., Pacitti, F., et al. (2020). Covid-19 pandemic and lockdown measures impact on mental health among the general population in Italy. Front. Psychiatry 11:790. doi: 10.3389/fpsyt.2020.00790

Sepulveda, A. R., Carrobles, J. A., and Gandarillas, A. M. (2008). Gender, school and academic year differences among Spanish university students at high-risk for developing an eating disorder: an epidemiologic study. BMC Public Health 8:102. doi: 10.1186/1471-2458-8-102

Skoda, E.-M., Teufel, M., Stang, A., Jöckel, K.-H., Junne, F., Weismüller, B., et al. (2020). Psychological burden of healthcare professionals in Germany during the acute phase of the COVID-19 pandemic: differences and similarities in 
the international context. J. Public Health 42, 688-695. doi: 10.1093/pubmed/ fdaa 124

Slavich, G. M., and Shields, G. S. (2018). Assessing lifetime stress exposure using the Stress and Adversity Inventory for Adults (Adult STRAIN): an overview and initial validation. Psychosom. Med. 80, 17-27. doi: 10.1097/PSY. 0000000000000534

Steinmetz, H., Batzdorfer, V., and Bosnjak, M. (2020). The ZPID Lockdown Measures Dataset for Germany. Germany: Leibniz Institute for Psychology Information.

Tang, W., Hu, T., Hu, B., Jin, C., Wang, G., Xie, C., et al. (2020). Prevalence and correlates of PTSD and depressive symptoms one month after the outbreak of the COVID-19 epidemic in a sample of home-quarantined Chinese university students. J. Affect. Disord. 274, 1-7. doi: 10.1016/j.jad.2020.05.009

Tanir, Y., Karayagmurlu, A., Kaya, Ý, Kaynar, T. B., Türkmen, G., Dambasan, B. N., et al. (2020). Exacerbation of obsessive compulsive disorder symptoms in children and adolescents during COVID-19 pandemic. Psychiatry Res. 293:113363. doi: 10.1016/j.psychres.2020.113363

Tritt, K., von Heymann, F., Zaudig, M., Söllner, W., Klapp, B., Loew, T., et al. (2010). Der Fragebogen ICD-10-Symptom-Rating (ISR) Kurzdarstellung der Normierung. Munich: Institut für Qualitätsentwicklung in der Psychotherapie und Psychosomatik.

Tritt, K., von Heymann, F., Zaudig, M., Zacharias, I., Söllner, W., and Loew, T. (2008). Development of the" ICD-10-Symptom-Rating"(ISR) questionnaire. Z. Psychosom. Med. Psychother. 54, 409-418. doi: 10.13109/zptm.2008.54.4.409

Wang, C., Pan, R., Wan, X., Tan, Y., Xu, L., McIntyre, R. S., et al. (2020). A longitudinal study on the mental health of general population during the COVID-19 epidemic in China. Brain Behav. Immun. 87, 40-48. doi: 10.1016/ j.bbi.2020.04.028

Wang, Y., Di, Y., Ye, J., and Wei, W. (2021). Study on the public psychological states and its related factors during the outbreak of coronavirus disease 2019 (COVID-19) in some regions of China. Psychol. Health Med. 26, 13-22. doi: $10.1080 / 13548506.2020 .1746817$

World Health Organization (WHO). (2020). Mental Health And Psychosocial Considerations During the COVID-19 Outbreak, 18 March 2020. Geneva: World Health Organization.
Xiao, H., Zhang, Y., Kong, D., Li, S., and Yang, N. (2020). Social capital and sleep quality in individuals who self-isolated for 14 days during the coronavirus disease 2019 (COVID-19) outbreak in January 2020 in China. Med. Sci. Monit. 26:e923921. doi: 10.12659/MSM.923921

Yip, P. S. F., Cheung, Y. T., Chau, P. H., and Law, Y. W. (2010). The impact of epidemic outbreak: the case of severe acute respiratory syndrome (SARS) and suicide among older adults in Hong Kong. Crisis 31, 86-92. doi: 10.1027/02275910/a000015

Zhou, X., Snoswell, C. L., Harding, L. E., Bambling, M., Edirippulige, S., Bai, $\mathrm{X}$, et al. (2020). The role of telehealth in reducing the mental health burden from COVID-19. Telemed. J. E Health 26, 377-379. doi: 10.1089/tmj. 2020.0068

Zhu, S., Wu, Y., Zhu, C. Y., Hong, W. C., Yu, Z. X., Chen, Z. K., et al. (2020). The immediate mental health impacts of the COVID-19 pandemic among people with or without quarantine managements. Brain Behav. Immun. 87, 56-58. doi: 10.1016/j.bbi.2020.04.045

Conflict of Interest: The authors declare that the research was conducted in the absence of any commercial or financial relationships that could be construed as a potential conflict of interest.

Publisher's Note: All claims expressed in this article are solely those of the authors and do not necessarily represent those of their affiliated organizations, or those of the publisher, the editors and the reviewers. Any product that may be evaluated in this article, or claim that may be made by its manufacturer, is not guaranteed or endorsed by the publisher.

Copyright (c) 2021 Schelhorn, Ecker, Lüdtke, Rehm, Tran, Bereznai, Meyer, Sütterlin, Kinateder, Lugo and Shiban. This is an open-access article distributed under the terms of the Creative Commons Attribution License (CC BY). The use, distribution or reproduction in other forums is permitted, provided the original author(s) and the copyright owner(s) are credited and that the original publication in this journal is cited, in accordance with accepted academic practice. No use, distribution or reproduction is permitted which does not comply with these terms. 